\title{
Research on the Course Reform of "Automobile Theory" Based on Project Driven Method
}

\author{
Ting-ting $\mathrm{LIU}^{1,{ }^{*}}$ and Zhi-hua $\mathrm{LI}^{1}$ \\ ${ }^{1}$ School of Mechanical Engineering, Hangzhou Dianzi University, Hangzhou, Zhejiang, \\ P.R. China \\ *liutingting817@163.com
}

Keywords: Automobile Theory, Course reform, Project riven method, Practice teaching.

\begin{abstract}
According to the characteristics of high theoretical density of "Automobile Theory" and the main problems in the current teaching, A new teaching reform is put forward, which is based on the combination of various teaching methods, interactive teaching, theory and practice teaching. The project-driven teaching method applied to the teaching of "Automobile Theory", through the construction, implementation and evaluation of classroom practice project, the project driven teaching process is completed. Project driven teaching method not only allows students to learn the theoretical knowledge in project implementation, but also cultivate the students' practical ability and the team cooperation spirit.
\end{abstract}

\section{Introduction}

As one of the three core courses in the vehicle engineering specialty, "Automobile Theory" has a very important position in the training target system of vehicle engineering. "Automobile Theory" course emphasis on theory, content is more abstract, teachers use the classic teaching methods in the classroom is difficult to achieve good teaching efforts, in the learning process, most of the students think the course is obscure and difficult to combine with practice. Therefore, it is very important to study the effective teaching method for the course of "Automobile Theory", which is very important for the training of vehicle engineering talents with innovation ability and engineering practice ability.

Project driven approach was summarized by American MBA education in the process of long-terming practice teaching[1]. In the implementation process, teachers concise the problems that need to be resolved in specific projects, students learn knowledge independently, conduct designing and implementation of the project and evaluate the results. In this paper, through the introduction of project driven method in the course of "Automobile Theory", in order to improve the students' ability of analysis and practice and improve the teaching effect, cultivate students' engineering practice ability.

\section{Current Situation of "automobile theory"}

The "Automobile Theory" has important position in the training target system of vehicle engineering specialty, but the effect is not satisfactory in practical teaching. The main reasons include the following two aspects.

"Automobile Theory" curriculum content is extensive, we need professional curriculum foundation. 
In the study of the vehicle and its components model, we need to use some of the advanced mathematics, engineering mechanics, mechanical design and principle, automotive structure and engine principle and other leading knowledge, this requires students to have a good foundation for the relevant professional courses, but now, many of these students is not very good at professional knowledge, resulting in a certain degree of difficulty in " Automobile Theory " course. Students in the learning process is always in a state of passive acceptance, which prone to the weariness and other negative emotions, this situation leads to students' learning initiative is not high, the content learning is slow, this state restricts the cultivation of students' innovation ability in a large extent.

"Automobile Theory" curriculum emphasis on theory, easily divorced from practice.

In the course teaching of "Automobile Theory", many teachers still use the traditional theory teaching and practice teaching separating method. In the theory class, the teacher explains the theoretical knowledge, in the experimental class, the teacher pays attention to the practical operation training, this is not only bad for students' digestion and absorption of knowledge, but also not good for the cultivation of students' ability, so as to cause the disconnection between theory and practice. As one of the core courses in the vehicle engineering specialty, The main purpose of "Automobile Theory" is to guide the practice and cultivate the talents of scientific research, so the combination of theory and practice is very important for students.

\section{The Ideas and Implementation Plan of "automobile theory" Curriculum Reform}

Strengthening and consolidation of vehicle engineering education system is an important part of engineering education. How to make the students learn and master the contents of the vehicle engineering courses in a limited time is the main problem to be solved in the course of "Automobile Theory". Specific methods and contents are as follows.

\section{Enrich Teaching Methods}

There is a lot of stress analysis and derivation teaching in "Automobile Theory". For example, the driving force and braking force of running car can be analyzed by the traditional method of writing on the blackboard, enable students to have more time to think and understand, they can follow the teacher's explanations, understand formula derivation process. The multimedia teaching methods due to the large amount of information, students do not have too much time to think and understand, so that teaching effect is not obvious.

There are still a lot of contents in "Automobile Theory" that related to the automobile construction, such as engine working process, these contents can be demonstrate in the form of multimedia teaching courseware, and some real models that difficult to display can be vividly presented to students, so that the original obscure content becomes intuitive[2].

The contents of "Automobile Theory" emphasis on theory, such as the fuel and economy calculation of electric vehicle, there is a lot of data calculation and formula derivation, the simple use of computing and rendering methods can not get satisfactory results. MATLAB simulation software has obvious advantages in data analysis and mapping, the interface is simple and easy to operate, while providing function and built-in module tool. In the teaching, we can use the method of engineering software to 
do analysis and calculations, which will not only draw and calculation accurately but also improve the students' enthusiasm for learning software.

These three teaching methods have their own characteristics, it is necessary to adopt different teaching methods to different teaching contents. Meanwhile, we can also use a variety of teaching methods to make the classroom more lively and interesting.

\section{Interactive Teaching Process}

Interactive teaching is to enable students to participate in the daily course, so that teachers and students can communicate effectively, improve the learning enthusiasm of students. Teaching process should not be just a simple face to face teaching in the classroom, such teaching dull and boring. In interactive teaching, teacher at dominant position, students are the main body, through the active participation of students to stimulate students' learning initiatives. For example, in the chapter that design the vehicle configuration to reduce the fuel consumption rate, there is a variety of ways to reduce fuel consumption, in interactive teaching, students can be divided into several groups, each group of students search information and discuss, produce their own courseware, one student as a representative introduces the idea of his group, other groups of students ask questions[3]. This will not only exercise the initiative ability of students but also active classroom atmosphere and students' comprehensive ability improved.

\section{Combination of Theory and Practice}

The contents of "Automobile Theory" emphasis on theory, If not combined with the engineering practice, the practice guidance can not be fully played. Through the analysis and summary of the contents, teachers find out the appropriate teaching method, by allowing students access to the actual car power devices, to enable students deepen their theoretical knowledge. Selected chapters such as automotive power plant parameters, teacher can give the students the actual parameters, students carry out the experiment of different transmission ratio, in this way, the students master the professional knowledge, but also exercise the method of scientific experiments.

In the practice teaching process, we can also add the design experiment in the original teaching, and introduce some automobile related mechanical system to carry on the example analysis, students themselves carry out the program design, do operations, analyze and process the experiment results.

\section{The Implementation Process of Project Driven Method}

In the implementation process of "Automobile Theory" based on project driven method, the problem in the course of "Automobile Theory" is divided into several small tasks, and the task is composed of specific projects, students carry out the relevant information collection, design, implement the project and show the results. In the teaching process, the project as a clue, the teaching content hidden in each project, let the students analyze the problem, solve the problem and summary. In this way, not only the learning task complete, but also cultivate students' ability to solve practical problems. Specific implementation steps are as follows.

\section{Project Construction}

Project construction is the key to the project driven "Automobile Theory" classroom teaching, project constructed, the entire project implementation process must revolve this project. Therefore, when the project is constructed, the following points should be 
reached: (1) The project should be closely integrated with practice, preferably from the practical work of the enterprise; (2) The project should be able to relate to the theory, which can guide the theory study; (3) Projects should be able to display, such as can be made into a finished product, or can draw a result curve, etc.; (4) The project should have a certain degree of difficulty, training students' ability and creativity.

\section{Project Implementation}

Design project content and carry out student grouping. According to the content of "Automobile Theory", select small projects that close to the actual production of enterprises. Select the following three items: The dynamic (maximum speed) index of the actual vehicle; The actual survey of buses, cars and SUVs; The driving force-driving resistance balance curve of actual vehicle. After the project is designed, students divided into groups, in order to help students communicate and cooperate, the students exchange their partners in different subjects, which also helps to cultivate students' cooperative spirit[4][5].

Consulting materials and make research plan. Teachers extract project-related knowledge, students according to project content and knowledge, collate information through various channels. After the data collection, the students formulate specific projects independently and complete the program, the teachers guide accordingly. The research plan includes determining the project name, the background of the project, the project schedule, the implementation of the project, the expected effect of the project, etc.. Through the study of these contents, the students understand the general process and methods of the study.

Complete specific project content. The students complete their work tasks independently according to the final work plan. On the basis of the discussion in the group, the team leader plays the role of the project manager, the task is divided, each member of the group is responsible for different project modules, and independent to complete their work tasks.

Summarize and complete project report. After the completion of the project, the students have to evaluate their work, including how to do the preparatory work, the problems encountered in the project, the implementation process and the method summary. The teacher finished the final work summary, performance evaluation of the students. Finally, each group elected one student to make the project report in front of the class to preach and summarize.

\section{Project Evaluation}

Project implementation process is the key point of the project evaluation. Teacher summarize the knowledge points of each project, evaluate the participating degree and the communicating ability of each student. After the evaluation of the use of knowledge points, the teacher analyzes the results obtained in the project and the existing problems, then puts forward some suggestions to revise the views, so that the students themselves sum up the pros and cons of the implementation process. Finally, the results of the evaluation at a certain proportion included in the final results of the course[6].

\section{Conclusions}

The continuous improvement of teaching method is an effective way to improve students' mastering knowledge ability and practical ability, it can improve students' learning initiative, the reform and implementation of teaching methods require teachers 
and students to work together. "Automobile Theory" is one of the three core courses in the vehicle engineering specialty, the teaching reform is of vital importance to the training of vehicle engineering professionals. The project driven method provides students with a relatively independent learning opportunities, through the implementation in "Automobile Theory" it will effectively mobilize the enthusiasm of the students to study independently, so as to improve the teaching effect of the specialized course, cultivate students' comprehensive use of knowledge and practical ability, enhance their skills and team spirit, it will play an important role in the cultivation of engineering application talents.

\section{Acknowledgements}

This research was financially supported by the National Natural Science Foundation of China (No.51305112 and No.51275141).

\section{References}

[1] Ze-ming QIU, Gao-liang WANG, Research on the project drive pedagogy in computer network practice education, Software Guide, 3(2011) 190-191. In Chinese.

[2] Ting-ting LIU, Zhong-min LIU, Discussion on the reform of "Automobile Theory",

Education Teaching Forum, 44(2015) 96-97. In Chinese.

[3] Ling LIN, Discussion of team and project driving teaching models in software engineering, Journal of Fujian Normal University(Natural Science Edition), 3(2011) 14-17. In Chinese.

[4] Yong-xue ZHANG, Implementation ways of automobile theory course and its effect analysis, Value Engineering, 8(2015) 299-300. In Chinese.

[5] Hong-ni ZHOU, Bao-hua WANG, Ying FENG, Discussion about the application of computer simulation technology in the course teaching of automobile theory, China Modern Educational Equipment, 9(2015) 80-83. In Chinese.

[6] Jin LI, Jie-ping CHEN, Ke-chuan YI, Reform on course evaluation of automobile theory, Journal of Anhui Science and Technology University, 26(2012) 80-82. In Chinese. 